\title{
"Great Technology, Football and...": Malaysian Language Learners' Stereotypes about Germany
}

http://dx.doi.org/10.1590/1982-8837154174

\section{Larisa Nikitina ${ }^{1}$, Zuraidah Binti Mohd Don ${ }^{2}$; Sau Cheong Loh $^{3}$}

\begin{abstract}
This study focuses on stereotypes about Germany, its culture and people, held by learners of German in a big public university in Malaysia. It examines not only the stereotypical representations of the target language country but also assesses its favourability and salience, which has not been done previously. The findings revealed that the students' stereotypes about Germany were varied and diverse. Also, they were overwhelmingly positive. The top three salient categories of images about Germany were related to technology, famous personalities - for the most part football players and scientists - and cars. The findings also indicated that very few references had been made to German culture and to its great cultural figures. The results of the present study suggest that students could benefit from a wider and deeper exposure to German culture in the language classroom.
\end{abstract}

Keywords: country stereotypes; Germany; foreign language education; German language

Zusammenfassung: Die folgende Studie untersucht stereotypische Wahrnehmungen in Bezug auf 'Deutsche' und 'Deutsche Kultur' unter den Studenten der Germanistik an einer großen öffentlichen Universität in Malaysia. Das Forschungsprojekt beleuchtet nicht nur stereotypische Repräsentationen des Landes 'Deutschland', sondern hinterfragt auch deren Bedeutung und Salienz - in einer Weise, wie es bisher noch nicht geschehen ist. Die Forschungsergebnisse haben erbracht, dass die auf Deutschland bezogenen stereotypischen Wahrnehmungen der Student(inn)en sowohl vielschichtig als auch vielfältig waren. Sie waren darüber hinaus auch überwiegend positiver Natur. An der Spitze des Deutschlandbildes der befragten Student(inn)en standen die drei Kategorien 'Technologie', 'berühmte Persönlichkeiten' - überwiegend Fußballer und Wissenschaftler - und 'Automobile'. Die Studie zeigte aber auch, dass es unter den Befragten nur ein sehr geringes Bewusstsein in Bezug auf 'Deutsche Kultur' und 'Kulturelle Persönlichkeiten' gab. Die dargelegten

\footnotetext{
${ }^{1}$ University of Malaya, Institute of Graduate Studies. Email: larisa@ siswa.um.edu.my, https://www.researchgate.net/profile/Larisa_Nikitina

${ }^{2}$ University of Malaya, Faculty of Languages and Linguistics. Email: zuraida@um.edu.my, http://www.researcherid.com/rid/C-1161-2010

${ }^{3}$ University of Malaya, Faculty of Education. Email: lohsch@um.edu.my, http://www.researcherid.com/rid/B-8881-2010
} 
Forschungsresultate legen den Schluss nahe, dass Student(inn)en deutlich von einer weit intensiveren Behandlung deutscher Kultur im Sprachunterricht profitieren würden.

Stichworte: stereotypische Wahrnehmungen über Länder; Deutschland; Fremdsprachenunterricht; Deutsche Sprache

\section{Introduction}

Language learners come to the classroom with their own preconceived images and cultural representations of the target language (TL) country, culture and speaking community. As DLASKA (2000: 260) noted, even in the beginner language classroom "stereotypes are always already there". Walter LIPPMANN (1922/1965: 3) who introduced the concept of stereotypes into the Social Sciences and Humanities argued that stereotypes are not only "pictures in the head" and important cognitive devices but they embed people's attitudes toward the surrounding world. As he wrote, "The stereotypes are [...] highly charged with the feelings that are attached to them" (LIPPMANN 1922/1965: 64).

The present study focuses on stereotypes about Germany held by learners of German in a big public university in Malaysia. A number of studies have explored language learners' cultural representations about Germany (ABRAMS 2002; CHAVEZ 2009; SchUlZ \& HAERle 1995; TAYlor 1977; WebBER 1990). The findings of these studies informed the teachers about possible pedagogical approaches to the teaching of culture in the language classroom. It should be noted that all of the previous empirical inquiries were done in Western educational contexts. Moreover, these studies examined only the content of the students' images about the TL country and they did not seek to assess favourability and salience of these representations.

The present study departs from this format. It not only examines the content of the students' stereotypical images about Germany but also assesses the attitudes embedded in the images and considers how important or salient these stereotypical images are. In this study, stereotypes are defined as "mental images about the target language country held by the learners of German". This article seeks to address the following questions: 
1. What stereotypical images do the beginner learners of the German language have about Germany, its culture and people?

2. Are the students' stereotypes about Germany positive or negative?

3. How salient are these images?

The present study has important pedagogical implications. Several researchers have pointed out that language educators have to face the fact that the language learners hold various kinds of stereotypes about the TL country, culture and native speakers (BYRAM \& KRAMSCH, 2008; DREWELOW, 2013). Therefore, language teachers must be prepared to address these stereotypes in the classroom. Exploring the students' stereotypical images about the TL country can help the language educators to make empirically informed decisions about developing the cultural component of the foreign language program.

\section{Literature Review}

\subsection{The Origins of the Construct}

Walter Lippmann (1889-1974) introduced the construct of stereotypes into the fields of the Social Sciences and Humanities in his seminal book "Public Opinion" (1922/1965). He famously described stereotypes as "pictures in our heads" (LIPPMANN 1922/1965: 3) and considered them as an important cultural and social phenomenon. LIPPMANN (1922/1965: 5) argued that our images about the surrounding world are culturally bound and that we tend to perceive various events, people and phenomena "in the form stereotyped for us by our culture". The inseparability of stereotypes from culture and their central function in human cognitive processes help to elucidate the tenacious and pervading nature of stereotypical representations about the world, people and various phenomena.

Lippmann's discourse on stereotypes presaged much of the ensuing empirical research on this psychological construct and many of the themes that he raised remain relevant until the present time. Importantly, Lippmann did not consider that stereotypes are necessarily negative. By contrast, he argued that they are natural and indispensable because 
as a cognitive device stereotypes help people to manage and process the incessant inflows of new information.

\subsection{Stereotypes about Germany and the Germans}

Stereotypes about Germany and the Germans have been explored, for the most part, within European and North American contexts and perspectives. For example, a number of studies are devoted to analyzing the origin and development of stereotypes about Germany in European literary sources (BELLER \& LEERSSEN 2007). BELLER (2007) pointed out that the origin of some stereotypes about Germany could be traced to the oeuvres by Julius Caesar ("Commentarii de Bello Gallico" published in print in 1469) and Publius Cornelius Tacitus ("Germania" published in print in 1470). In these classical texts, the ancient Germans are described as blond, physically strong, brave in battle people who are also heavy drinkers. These images have become the 'archetypal' images of the German people and for several centuries they have been recurring in various discourse modes (cf. BELLER 2007).

Researchers recognize that, notwithstanding their inflexible nature stereotypes about other countries and nations, do undergo changes and that the content of such stereotypes varies between historical, social and cultural contexts. The new additions to the older images reflect the Zeitgeist and the changing social and cultural mores. Thus, European travellers and writers in the $18^{\text {th }}$ and $19^{\text {th }}$ centuries introduced several enduring images about Germany and the German people. One of the most positive images was contributed by Mme de Staël (1766-1817) who described Germany in her oeuvre De l'Allemagne (1810/1813) as the "land of poets and philosophers" (DE STAËL cited in BELLER 2007: 161). The emergence of Germany as a military and industrial power in the $19^{\text {th }}$ century brought forth the images of the Germans' "diligence, efficiency, obedience, systematic thoroughness, a penchant for neatness" while Germany's role in World War II instituted the negative images evoking the Nazi regime (BELLER 2007: 162).

The first empirical study that examined stereotypical images about the German people was done by KATZ and BRALY (1933) among students in an American university. The researchers gave their respondents a list of 84 adjectives describing character traits and 
asked them to select the characteristics for various national groups, including the Germans. As the findings revealed, the top five characteristics given by the respondents to the German people had been "scientifically-minded", "industrious", "stolid", "intelligent", and "methodical". This prompted Katz and Braly to comment that the students' views about the German people were "consistent with the popular stereotype to be found in newspapers and magazines" (KATZ \& BRALY 1933: 285).

Studies on stereotypes about Germany held by the learners of German are welldocumented. This topic has been of interest to researchers since the 1970s, though the available studies were done mostly in the US educational context. In one of the earlier studies on cultural representations about the target language country, TAYLOR (1977) asked the beginner learners of German in an American college the following three questions: "What geographical places come to your mind when you think of Germany?"; "What other associations do you have with Germany, past and present?"; and "Which are Germanspeaking countries?". The first question received such responses as "Munich, Berlin, Rhine, Hamburg, Black Forest, Berlin Wall, Frankfurt, Cologne, Heidelberg, Alps, Bonn, Bavaria” (TAYLOR 1977: 112). Among the frequently given answers to the second question were "folklore, wars, Hitler, beer, ties through family and/or friends, Olympics, classical music, food, Nazism". The students had also provided several "stereotyped national traits" which the author did not specify. In their answers to the third question the students mentioned "Germany, Austria, Switzerland, Luxembourg, Belgium" among the German-speaking countries. Discussing the findings Taylor (1977) noted that the respondents' images about the TL country were of a highly stereotypical nature.

SCHULTZ and HAERLE (1995) who investigated stereotypes about the German people held by learners of German in an American college asked their respondents to complete the phrase "Die Deutschen ...". The analysis of the data revealed that the images could be separated into eight main categories, such as: (1) German people's personal characteristics (e.g., "hardworking”, "friendly", “intelligent”); (2) their beer-drinking habit; (3) German-made cars (e.g., "they make excellent cars"); (4) the references to country or German language (e.g., "beautiful country", "difficult language”); (5) culture and schooling (e.g., "(they) have interesting/rich culture", "(they are) well-educated"); (6) physical attributes (e.g., "good looking", "tall”); (7) references to history or historical events (e.g., 
“interesting history"); and (8) food and eating ("they eat sauerkraut"). As these findings indicate, there was a lack of references to important political events in the country. Also, as SCHULTZ and HAERLE (1995) noted, conspicuously lacking were images concerning cultural and scientific achievements.

In another study, Abrams (2002) explored images that American students learning German have about various German-speaking countries. The findings revealed that the prevalent images about Germany concerned beer, various foods (e.g., "bratwurst") and the country's rich history. There were only few references to the German people who the students described as "friendly" and "punctual". Several other answers about Germany provided by the respondents were "soccer", "different school system" and "the German language".

A study by CHAVEZ (2009) focused on the language learners' stereotypes about the target language rather than the TL country or the native speakers. As the researcher noted, the images of the German language promoted in the mass media, in the TV programs and in the movies were that of "a harsh, throaty, or "phlegmy' language" (CHAVEz 2009: 8). The perceived harshness of the language is often extrapolated to native speakers of German who are viewed as "aggressive" people (CHAVEZ 2009: 17). However, as Chavez found out, the beginner learners of German lacked such negative notions about the target language. An unexpected finding was that some students had chosen to learn the language because its "harsh-sounding" character made it unique and not a "sissy language". In addition, the students described German as a "strange" and "difficult language" with "backwards" grammar in a sense that it had a "backwards syntax of English" (CHAVEZ 2009: 6).

\subsection{Favourability of Language Learners' Country Stereotypes about Germany}

Some studies on stereotypes about Germany made attempts to classify the images into positive, negative or neutral. For example, Schulz and HAERLE (1995) divided the students' images into positive and negative and they concluded that their respondents had mostly positive images about the TL country and the German people. TAYLOR (1977: 113) also evaluated some of the students' images as positive, especially those relating to "good 
old Germany". However, the previous studies did not make explicit attempts to empirically assess favourability of the students' representations about Germany. The researchers relied on 'commons sense' and their own subjective judgement to describe the images as positive or negative. For example, SchUlz and HAERLE (1995) classified the descriptors "stolz" ("proud") or "mit viel Gefühl" ("with much feelings", "emotional") as positive images. The problem is that the students who had provided these images could have evaluated them differently. For example, the characteristic "stolz" could be assigned a negative connotation by some people while others could view this trait as neutral.

To avoid this ambiguity, some researchers asked their respondents to give a mark to each of the images about the TL country that they had written (NIKITINA \& FURUOKA 2013). The present study employs a similar technique because this allows a more precise analysis of the language learners' attitudes toward the TL country.

\section{Method}

\subsection{Participants}

The participants in this study were 26 beginner learners of German in University of Malaya, Malaysia. The students learned German as a generic course. This means that they chose this particular language program among several other European and Asian languages offered by the University based on their preference or personal interest.

There were more male $(\mathrm{n}=15,57.7 \%)$ than female $(\mathrm{n}=11,42.3 \%)$ students among the respondents; the age of the students ranged from 20 to 24 years old. The participants were mostly Malaysians ( $\mathrm{n}=22 ; 84.6 \%)$. The international students ( $\mathrm{n}=4$ or $15.4 \%$ ) hailed from Spain ( $\mathrm{n}=2)$, Uzbekistan ( $\mathrm{n}=1)$ and Bangladesh $(\mathrm{n}=1)$. 


\subsection{Data Collection and Instrument}

Data for this study were collected from the students in all three sections of the German language program in the academic year 2012/2013. The students were given photocopied forms - one per student - that contained the open-ended question "What images or mental pictures come to your mind when you hear the words 'Germany' and 'German'?”.

The participants were asked to write as many words or short phrases as they thought was necessary to convey their images and impressions about the TL country. After the students had finished writing the images they were instructed to give a mark (i.e., favourability rating) to each image in their lists using a scale from -2 (for "a very negative image") to +2 (for "a very positive image"). The form also contained several questions about the respondents' age, gender and nationality.

\subsection{Data Organization and Analysis}

First of all, the images about Germany written by the students were typed ad verbatim in the Microsoft Word file format. Then they were grouped into categories. Content analysis approach was used for this purpose. Content analysis refers to "the intellectual process of categorizing qualitative textual data into clusters of similar entities, or conceptual categories, to identify consistent patterns and relationship between variables or themes" (JULIEN 2008: 120).

Adopting content analysis entails using open-coding to separate the data into categories or clusters or images. This means that the data rather than theory determine the codes and the headings given to the categories of images (MACKEY \& GASS 2005; RYAN \& BERNARD 2003). In other words, the researcher makes no a priori decisions as to which categories might emerge from the analysis of the data. In the present study, the decisionmaking process concerning the formation of the categories of images about the TL country was as follows. First of all, we did not aim at a fine-grained analysis that would result in a greater number of highly homogenous categories of images. Rather, when grouping the 
images into the categories we sought to achieve coherent and logically consistent clusters of representations about Germany. This approach was entirely in spirit with the content analysis which should be data driven and where the categories should reflect the data set.

To be more specific, in the first stage of the analysis, we grouped similar images into clusters and assigned these clusters labels based on the words, short phrases or descriptors they contained, as recommended by JULIEN (2008). For example, we placed the images "cars", "Volkswagen", "BMW" and "Mercedes Benz" into the same group and labelled this groups "Cars" because the majority of the answers referred to - literally "cars". The same logic was adopted throughout the analysis of the data. The resultant 'larger canvases' of the students' imagery helped us to distinguish what country-related aspects (e.g., culture, food, politics, technology, people, etc.) were particularly wellrepresented; they also allowed us to see which features were lacking among the students' representations about the TL country. There were several idiosyncratic images that could not form coherent categories with the rest of the answers provided by the students. These images were placed in the category "Others".

\subsection{Calculating Favourability of the Categories of Images}

In the second stage of the analysis, we used the marks that the students had assigned to each of the images in their lists to calculate favourability (or mean valence) of the categories of images about Germany. A similar method was employed by NIKITINA and FURUOKA (2013) to assess favourability of the clusters of images about China held by learners of Mandarin. In this approach, first of all, the summation of the favourability ratings of all the images in a category is calculated. Secondly, the sum total is divided by the number of the images in the category. In the mathematical terms the calculations can be expressed as:

$$
M V_{j}=\frac{\sum_{j=1}^{n_{j}} V_{j i}}{n_{j}}
$$


where $M V_{j}$ is the mean valence value of category $j ; V_{j i}$ is the valence rating given by student $i$ to image $j ; n_{j}$ is the frequency with which image $j$ was mentioned. For example, the image "Hamburg" was mentioned three times $\left(n_{j}=3\right)$. Each student assigned his or her own favourability rating to this image on the scale ranging from -2 to +2 . Employing formula (1), the mean valence value of the image "Hamburg" was calculated as being equal to $1.3333(M V=1.3333)$.

Based on their mean valence (MV) values the categories of images could be further divided into highly positive $(1.500 \leq \mathrm{MV} \leq 2.000)$, positive $(0.500 \leq \mathrm{MV}<1.500)$, mildly positive $(0<\mathrm{MV}<0.500)$, neutral $(\mathrm{MV}=0)$, mildly negative $(-0.500<\mathrm{MV}<0)$, negative $(-$ $1.500<\mathrm{MV} \leq-0.500)$ and highly negative $(-2.000 \leq \mathrm{MV} \leq-1.500)$.

\subsection{Overall or Composite Favourability}

To compute the overall favourability or composite mean valence (CMV) of the stereotypical images about Germany, we calculated the summation of all the favourability ratings given to the images about Germany and then divided the sum total by the total number of the images provided by the students. Mathematically this can be expressed as:

$C M V=\frac{\sum_{j=1}^{N} V_{j i}}{N}$

where $V_{j i}$ is the valence rating given to image $j$ by student $i$ and $N$ is the total number of the images about Germany.

\subsection{Calculating Salience of the Categories of Images}

As a next step of the data analysis we assessed salience or prominence of the images about Germany by computing Modified free-list salience (MFLS) index developed by Smith et al. 
(1995). The computations of the salience index were done using ANTHROPAC 4.0 software (BORGATTI 1992).

It should be noted that due to a highly heterogeneous nature of images in the category labelled "Others" favourability and salience of this category were not calculated. However, we included the images in the category "Others" when reporting the total number of the images about Germany provided by the respondents as well as the overall favourability (CMV) of the students' attitudes toward the TL country.

\section{Findings}

In response to the open-ended question, the respondents provided a total of 197 images. The longest list contained 19 representations about Germany while the shortest list had 2 answers. The images about Germany were separated into 14 categories (excluding the category "Others"), which are shown in Table 1. The table reports the following findings about each of these categories: favourability or mean valence (MV); the rank according to mean valence (MVR); the number of images (n) the category contains; the rank according to the number of images in the category (NR); the category's salience index (SI); the rank according to the salience index (SR).

As the findings revealed, five of the fourteen categories of images about Germany were highly positive $(1.500 \leq \mathrm{MV} \leq 2.000)$; eight were positive $(0.500 \leq \mathrm{MV}<1.500)$ and one category was negative $(-1.500<\mathrm{MV} \leq-0.500)$. A more detailed discussion about the content,

favourability, size and salience of these categories of images is offered in the following subsections.

\subsection{Highly Positive Categories of Images about Germany}

The highly positive categories about Germany were: "Cars" (MV=1.952), "Technology, science and engineering" (MV=1.778), "Multinational companies and manufacturing" 
$(\mathrm{MV}=1.667)$, "Food and beer" $(\mathrm{MV}=1.615)$ and "Beautiful and peaceful country" $(\mathrm{MV}=1.500)$. Three of these categories were also among the top five most voluminous, namely, "Cars" ( $n=21 ; N R=3)$, “Technology, science and engineering” $(n=18 ; N R=4)$ and "Food and beer" (n=13; NR=5).

The category with the highest mean valence - "Cars" (MV=1.952) - contained general references to cars (e.g., "automobile", "cars") as well as the images referring to specific car makers. The most popular of them was "Volkswagen"; it was followed by "BMW", "Mercedes Benz", "Porsche" and "Audi". One student wrote "Das Auto", which means "the car" in German; this phrase is also used as the advertisement slogan for the "Volkswagen" car. Almost all images in this category were given the highest positive mark +2 by the respondents; only one student assigned the mark +1 to the image "Volkswagen".

Table 1: Categories of stereotypical images about Germany, their favourability, size and salience

\begin{tabular}{|c|c|c|c|c|c|c|}
\hline Category & $\begin{array}{l}\text { Mean } \\
\text { Valence } \\
\text { (MV) }\end{array}$ & $\begin{array}{l}\text { Mean } \\
\text { Valence } \\
\text { Rank } \\
\text { (MVR) }\end{array}$ & $\begin{array}{l}\text { Number } \\
\text { of } \\
\text { Images } \\
\text { (n) }\end{array}$ & $\begin{array}{l}\text { Rank by } \\
\text { Size (NR) }\end{array}$ & $\begin{array}{l}\text { Salience } \\
\text { Index } \\
\text { (SI) }\end{array}$ & $\begin{array}{l}\text { Salience } \\
\text { Rank } \\
\text { (SR) }\end{array}$ \\
\hline
\end{tabular}

\begin{tabular}{lllllll}
\hline Cars & 1.952 & 1 & 21 & 3 & 0.296 & 3 \\
\hline $\begin{array}{l}\text { Technology, science } \\
\text { and engineering }\end{array}$ & 1.778 & 2 & 18 & 4 & 0.317 & 1 \\
\hline $\begin{array}{l}\text { Multinational } \\
\text { companies and } \\
\text { manufacturing }\end{array}$ & 1.667 & 3 & 6 & 12 & 0.104 & 13 \\
\hline
\end{tabular}

\begin{tabular}{lcccccc}
\hline Food and beer & 1.615 & 4 & 13 & 5 & 0.133 & 10 \\
\hline $\begin{array}{l}\text { Beautiful and peaceful } \\
\text { country }\end{array}$ & 1.500 & 5 & 6 & 12 & 0.111 & 12 \\
\hline $\begin{array}{l}\text { Advanced and } \\
\text { important country }\end{array}$ & 1.462 & 6 & 13 & 5 & 0.189 & 7 \\
\hline Football and sport & 1.385 & 7 & 13 & 5 & 0.243 & 5 \\
\hline Cities and sites & 1.364 & 8 & 22 & 2 & 0.252 & 4 \\
\hline
\end{tabular}


Nikitina, Don; Loh - Stereotypes about Germany

\begin{tabular}{lcccccc}
\hline $\begin{array}{l}\text { Traditional and } \\
\text { popular culture }\end{array}$ & 1.308 & 9 & 13 & 5 & 0.195 & 6 \\
\hline Country and lifestyle & 1.167 & 10 & 12 & 9 & 0.135 & 9 \\
\hline eather and climate & 1.000 & 11 & 4 & 14 & 0.086 & 14 \\
\hline $\begin{array}{l}\text { People and famous } \\
\text { personalities }\end{array}$ & 0.757 & 12 & 37 & 1 & 0.310 & 2 \\
\hline Language & 0.556 & 13 & 9 & 11 & 0.116 & 11 \\
\hline History & -1.200 & 14 & 10 & 10 & 0.149 & 8 \\
\hline
\end{tabular}

Total*

197

Composite MV

\subsection{8}

$(C M V)^{*}$

Note. *The images in the "Others" category were aggregated in the computations of these values.

The category with the second highest mean valence was "Technology, science and engineering" (MV=1.778). It included such images as "engineering", "great technology", "relativity", "advances in engineering knowledge" and "U-boat". One image ("U-boat") received the neutral rating 0 ; two images were rated +1 and all the rest were marked +2 by the students.

In the category "Multinational companies and manufacturing" (MV=1.667) were placed the names of famous German multinational corporations and conglomerates, such as "Bosch", "Mertz" and "Siemens", and also the images referring to manufacturing activities (e.g., "factory manufacturing", "industry"). For the most part, the images in this cluster received the highest rating +2 and only two images were rated +1 .

The category "Food and beer" $(\mathrm{MV}=1.615)$ contained several images of general nature (e.g., "nice food") and the references to particular German dishes and foods (e.g., "sausages", "German hotdog", "currywurst", "pretzels"). Also included in this category were the answers relating to beer, such as "beer" and "good beer". For the most part the images in this category were rated +2 . There were no negative or neutral images in this cluster. 
Nikitina, Don; Loh - Stereotypes about Germany

The following in the mean valence value group of images was labelled "Beautiful and peaceful country" (MV=1.500). It included the representations "beautiful country", "beautiful country side", "beautiful landscape" and the descriptions referring to a peaceful atmosphere in the TL country (e.g., "peace", "peaceful" and "peaceful country"). All these images were positive and half of the answers received the highest rating +2 .

\subsection{Positive Categories of Images about Germany}

Among the positive categories of images about Germany, the cluster "Advanced and important country" (MV=1.462) had the highest mean valence. It contained the images that referred to Germany's status as economically advanced and developed country (e.g., "advanced country", “developed country", “development”, "good economy”, "prosperous future") and as an important European nation (e.g., "important country in Europe", "the future of Europe in is Germany"). Seven images in this category were given the highest rating +2 and six images were marked +1 by the students.

In the category "Football and sport" $(\mathrm{MV}=1.385)$ some images were of a general nature (e.g., "football, "German football" and "football - World Cup") while others mentioned particular German football clubs (e.g., "Bayern Munich", "Borussia Dortmund"). The majority of the images in this category were marked +2 by the language learners and only one image ("football") was given the negative rating.

The cluster labelled "Cities and sites" (MV=1.364) with its 22 images was among the most voluminous categories of images about Germany $(\mathrm{NR}=2)$. The students mentioned such cities as "Berlin", "Hamburg" and "Munich". Among the popular landmarks and sites in Germany were included "Berlin Wall", "Brandenburg Gate", "Frankfurt airport" and "Reichstag". Some students simply wrote "buildings". The majority of the images in this category were rated +2 or +1 by the respondents. Five images received the neutral rating 0; among them were "Berlin Wall", "Frankfurt airport", "Hamburg" and "Reichstag". There were no negatively rated images in this category. 
The category "Traditional and popular culture" (MV=1.308) contained an assortment of images referring to traditional German culture (e.g., "Oktoberfest") and to the contemporary pop culture (e.g., "song "99 Luftballons"); some images were rather general (e.g., "culture", "music", "good culture"). Only one student gave the negative rating -2 to the image "Oktoberfest", while another respondent assigned the neutral rating 0 to the same image. The rest of the representations in this category received the positive ratings +2 and +1 .

The "Country and lifestyle" cluster $(\mathrm{MV}=1.167)$ contained such characteristics of Germany as a "disciplined country", a "good country in general" and a "nice country". Also included in this category were the references to the general tenor of life in Germany (e.g., "order", "organization" and "harmony"). Two students mentioned high taxes and free education (i.e., "high tax", "education is free if you master the German language"). Several respondents provided the descriptions of the German national flag (e.g., "the flag colour is yellow and black"). One image in this category was rated negatively (i.e., "grey colour" -1) and one image received the neutral rating 0 (i.e., "the flag colour is yellow and black"). The rest of the representations were assigned the positive ratings +2 or +1 . The following category "Weather and climate" (MV=1.000) contained the references to the climate and weather in Germany (e.g., "there are four seasons", "nice weather"). The images in this category were given either the neutral rating 0 or the positive rating +2 .

The most voluminous category of images about Germany was "People and famous personalities" $(n=37 ; N R=1 ; M V=0.757)$. Some of the images concerned the typical behaviour of the German people as perceived by the language learners (e.g., "people try their best to improve their country", "children sleep early"). Several images referred to character traits and attributes (e.g., "disciplined people", "friendly people", "hardworking people", "nice people", "punctual people", "patriotic people" "people have analytical mind" and "people have very strong will"). For the most part, the images in this category were rated positively. However, several images relating to the German people character traits were given the negative mark -1 (e.g., "old fashioned people", "strict people", "boring people" and "people are serious and not funny"). Among the famous German personalities included in this category the students mentioned German Chancellor Angela Merkel; football players Miroslav Klose, Roy Makaay and Michael Ballack; scientists and Nobel 
Prize laureates Albert Einstein and Fritz Haber; industrialist and inventor Robert Bosch. Several respondents mentioned Adolf Hitler. For the most part, the famous persons were rated positively by the students. The exceptions were Adolf Hitler and, somewhat oddly, Angela Merkel and Fritz Haber; these images received either negative or the neutral ratings.

The category "Language" (MV=0.556) had the lowest average favourability among the positive clusters of images about Germany. This was due to the fact that a considerable share of the images described German as a "difficult language" or a "language more difficult than English". These images were marked either as neutral (0) or as negative (-2), which contributed to the comparatively low mean valence of the category "Language". On the positive side, the students considered German as a "unique language" and a "powerful language". These images received the highest positive rating +2 from the respondents.

\subsection{Negative Category of Images about Germany}

"History" (MV=-1.2) was the only category of images about Germany that had a negative mean valence. In this category the lowest rated images were "World War II" and "Nazi"; they received the rating -2 from the respondents. Several images received the neutral rating 0 ; among them were "important past history" and "interesting history". Only one image in the category "History" received the positive rating +1, which was "Vikings".

\subsection{Composite Mean Valence}

The overall favourability of the images about Germany was positive as reflected in the composite mean valence value $(\mathrm{CMV}=1.198)$. This means that despite the presence of several negative images about Germany the overall perceptions of the TL country by the language learners were good and positive. 


\subsection{Salience of the Categories of Images about Germany}

As shown in Table 1, the top five most salient categories of images about Germany were "Technology, science and engineering" ( $\mathrm{SI}=0.317 ; \mathrm{SR}=1)$, "People and famous personalities" ( $\mathrm{SI}=0.310 ; \mathrm{SR}=2)$, “Cars" $(\mathrm{SI}=0.296 ; \mathrm{SR}=3)$, "Cities and sites" $(\mathrm{SI}=0.252$; $\mathrm{SR}=4)$ and "Football and sport" $(\mathrm{SI}=0.243 ; \mathrm{SR}=5)$. The least salient category was "Weather and climate" ( $\mathrm{SI}=0.086 ; \mathrm{SR}=14)$.

Generally, the categories' salience and size tended to align. In other words, for the most part, there were no great disparities between a category's salience rank and its size rank. However, there were two exceptions. Thus, the category "Technology, science and engineering" had the highest salience rank $(\mathrm{SR}=1)$ but was only fourth in size $(\mathrm{NR}=4)$. This means that though the images in this category came to the minds of the respondents readily, which attests to their high salience, they tended to be mentioned by fewer respondents compared to the images in the categories "People and famous personalities" or "Cars". By contrast, the category "Food and beer" had a low salience rank $(\mathrm{SR}=10)$ but the images it contained were mentioned quite frequently $(\mathrm{NR}=5)$.

For several categories of images salience ranks and frequency ranks had the same numerical values. For example, in the cases of the clusters "Cars" $(\mathrm{SR}=3 ; \mathrm{NR}=3)$ and "Football and sport" $(\mathrm{SR}=5 ; \mathrm{NR}=5)$ the high salience ranks were matched by the size ranks. This indicates that a considerable number of the language learners had strongly associated Germany with cars, football and sport. On the other hand, the categories "Country and lifestyle" ( $\mathrm{SR}=9 ; \mathrm{NR}=9)$, "Language" $(\mathrm{SR}=11 ; \mathrm{NR}=11)$, "Beautiful and peaceful country" $(\mathrm{SR}=12 ; \mathrm{NR}=12)$ and "Weather and climate" ( $\mathrm{SR}=14 ; \mathrm{NR}=14)$ not only had low salience ranks but they were also small in size. This means that the images concerning weather as well as the representations of Germany as a beautiful and peaceful country had rather weak associations with the TL country in the minds of the language learners.

The categories where salience ranks were very closely aligned with frequency ranks were: "People and famous persons" ( $\mathrm{SR}=2 ; \mathrm{NR}=1)$, "Cities and sites" $(\mathrm{SR}=4 ; \mathrm{NR}=2)$, "Culture" $(\mathrm{SR}=6 ; \mathrm{NR}=5)$, "Advanced and important country" $(\mathrm{SR}=7 ; \mathrm{NR}=5)$ and "Multinational companies and manufacturing" $(\mathrm{SR}=13 ; \mathrm{NR}=12)$. The finding that the salience ranks and 
the frequency ranks of these categories of images coincided or were closely aligned indicates that the relevant representations about Germany were consistent and homogenous at the group level. In other words, some of the images were strongly associated with Germany in the minds of many of the respondents. By contrast, several images had weaker associations with the TL country and they were not mentioned by many students.

Concerning salience and favourability of the categories of images about Germany, two among the highly positive clusters of images - "Cars" ( $\mathrm{SR}=3 ; \mathrm{MVR}=1)$ and "Technology, science and engineering" $(\mathrm{SR}=1 ; \mathrm{MVR}=2)$ - were also among the top five most salient. It should be noted that the least favourable category "History" (MV=-1.200; $\mathrm{MVR}=14$ ) occupied a middle position according to its salience $(\mathrm{SR}=8)$.

\section{Discussion and Conclusion}

The present study investigated stereotypes about Germany held by Malaysian university students learning the German language. Besides exploring the content of the stereotypical images, it also assessed their favourability and salience, which had not been done in the previous studies on stereotypes held by the learners of German.

The findings of the present inquiry aligned with the results reported in the previous studies. For example, the Malaysian students described the German people as "friendly", "punctual", "disciplined", "have analytical mind" and "hard-working". These images agree with the character traits assigned to the native speakers of German in the studies done by KATZ and Braly (1933), Schulz and HAERle (1995) and ABRAMS (2002). However, in contrast to some of the previous studies (e.g., Schulz \& HAERLE 1995) the Malaysian respondents provided no reference to the physical attributes of the German people.

The findings indicated that, for the most part, the language learners in various parts of the world tended to share their views about Germany, its culture and language. For example, similar to the American college students, the participants in the present study described Germany as a "beautiful country" that produces excellent cars; as a country that has rich and interesting history, culture and a unique as well as difficult language (cf. ABRAMS, 
2002; ChaVez 2009; Schulz \& HAERle 1995; TAYlor 1977). Also, the categories of images distinguished in the present study aligned with those reported by Schulz and Haerle (1995).

There were some differences in the findings between the present and the previous studies. For example, the Malaysian students made a considerable amount of references not only to German cars but also to the high level of technological, engineering and scientific advancement in the country and to Germany's status as an industrial country with big multinational companies and corporations. Also - and this was a rather unexpected finding - the references to soccer and the names of several German football league teams (e.g., "Bayern Munich", "Borussia Dortmund") featured prominently among the Malaysian students' images about Germany. Previously, references to football, and those were few in number, were reported in ABRAMS' (2002) study only.

The findings revealed that the Malaysian learners of German who participated in this study had predominantly positive attitudes toward the TL country. This could be attributable to the fact that the students had voluntarily chosen to learn German based on their preference for this particular foreign language or due to their interest in the TL country. The students' positive attitudes toward Germany and the Germans are reflected in the positive mean valence values of almost all of the categories of images about Germany, except for the cluster "History" (MV=-1.200), and in a high composite mean valence value $(\mathrm{CMV}=1.198)$. Unfortunately, it is not possible to compare the favourability of the categories of images about Germany and the attitudes toward the TL country between the present and the previous studies because of the differences in the research methodologies. The earlier studies did not use favourability ratings to assess the students' attitudes. Also, salience of the German language learners' representations about the TL country has not been assessed in the earlier academic inquiries.

The current study has some limitations. For example, its findings may not be applicable in the culturally different from the present study settings. This is due to the fact that stereotypes about other countries are culturally-bound and, therefore, they cannot be completely the same in different cultural contexts. Besides, this study focused on language learners at a tertiary level. Therefore, the findings may not be generalizable for younger age 
groups of language learners because their worldview is more limited compared to that of young adults. A final caveat concerns a small number of participants in this study, which limits the generalizability of the findings. Despite these limitations, the findings reported in this article may be useful for comparing the language learners' representations of Germany, its culture and people in various educational and cultural settings. More importantly, the techniques and approaches demonstrated in this study can be used, with some modifications if needed, in future scholarly inquires on language learners' stereotypes about the TL country.

The findings reported in this study have some pedagogical implications. Though the mental representations about Germany were multifarious and diverse, a closer scrutiny of the stereotype content revealed some important omissions in the students' images. For example, among the various famous personalities mentioned by the respondents there were no great cultural figures from 'the land of poets and philosophers'. The football players featured most prominently among the famous Germans in the students' lists; they were followed by renowned scientists. This fact does not necessarily mean that the students were not familiar with the names Johann Sebastian Bach, Richard Wagner, Johann Wolfgang von Goethe, Heinrich Heine, Immanuel Kant or Friedrich Nietzsche. But this does point to the fact that the prime cultural figures were not among the most readily available images of Germany in the students' minds. At the same time, the images referring to German culture were either too general (e.g., "music") or limited to popular stereotypes (e.g., "Oktoberfest"). These findings indicate that the Malaysian students may benefit from a wider exposure to German culture in the language classroom. The language educators may want to introduce important cultural figures to the learners, especially in view that these figures have a great cultural significance and importance of in the context of Germanspeaking countries.

\section{Bibliographical references}

ABRAMS, Z. I. Surfing to cross-cultural awareness: using internet-mediated projects to explore cultural stereotypes. In: Foreign Language Annals 35(2), 2002, 141-153. 
Nikitina, Don; Loh - Stereotypes about Germany

BELLER, M. Germans. In: Beller, M. and J.T. Leerssen (eds.). Imagology: The cultural construction and literary representation of national characters: A critical survey. Amsterdam/New York, Rodopi, 2007, 159-165.

BELLER, M. \& LEERSSEN, J.T. Imagology: The cultural construction and literary representation of national characters: A critical survey, Amsterdam/New York, Rodopi, 2007.

BORGATTI, S. P. ANTHROPAC 4.0. Columbia, Analytic Technologies, 1992.

BYRAM, K., \& KRAMSCH, C. Why is it so difficult to teach language as culture? In: The German Quarterly 81(1), 2008, 20-34.

CHAVEZ, M. (2009). Learners' descriptions of German pronunciation, vocabulary, and grammar: a folk linguistic account. In: Die Unterrichtspraxis / Teaching German 42(1), 2009, 1-18.

DLASKA, A. Integrating culture and language learning in institution-wide language programmes. In: Language, Culture and Curriculum 13(3), 2000, 247-263.

DREWELOW, I. Impact of instruction on shaping or reshaping stereotypical cultural representations in an introductory French course. In: Foreign Language Annals 46(2), 2013, 157-174.

JULIEN, H. Content analysis. In: Given L.M. (ed.), The SAGE encyclopaedia of qualitative research methods, Vol.1. Thousand Oaks, CA, SAGE Publications, 2008, 120-121.

KATZ, D., \& BRALY, K.W. Racial stereotypes of one hundred college students. In: Journal of abnormal psychology 28,1933, 280-290.

LiPPMANN, W. Public opinion, New York, Free Press Paperback, 1922/1965.

MACKEY, A., \& GASS, S. M. Second language research: Methodology and design, Mahwah, NJ, Lawrence Erlbaum Associates, 2005.

NiKiTINA, L., \& FURUOKA, F. “Dragon, Kung Fu and Jackie Chan...”: stereotypes about China held by Malaysian students. In: TRAMES 17(2), 2013, 175-195.

RyAn, G. W., \& BERnARD, H.R. Techniques to identify themes. In: Field Methods 15(1), 2003, 85109.

Schulz, R. A., \& HAERlE, B.M. "Beer, fast cars, and ...": Stereotypes held by U.S. college-level students of German. In: Die Unterrichtspraxis / Teaching German 28(1), 1995, 29-39.

SMith, J. J., FurbeE, L., MAYnARD, K., Quick, S., \& Ross, L. Salience counts: a domain analysis of English color terms. In: Journal of Linguistic Anthropology 5(2), 1995, 203-216.

TAYLOR, I. C. Beware of cultural clichés. In: Die Unterrichtspraxis / Teaching German 10(2), 1997, 108-114.

WEBBER, M. J. Intercultural stereotypes and the teaching of German. In: Die Unterrichtspraxis / Teaching German 23(2), 1990, 132-141.

Recebido em 17/06/2014

aceito em 27/08/2014

Pandaemonium, São Paulo, v. 17, n. 24, Dez. /2014, p. 154-174 